\title{
An equity-focussed social impact assessment of the Lower Hunter Regional Strategy
}

\section{Venessa L. Wells ${ }^{\mathrm{A}, \mathrm{C}}$, Karen E. Gillham ${ }^{\mathrm{A}}$, Milly Licata ${ }^{\mathrm{A}}$ and Anne M. Kempton ${ }^{\mathrm{B}}$}

\author{
${ }^{\mathrm{A}} H u n t e r$ New England Population Health, \\ Hunter New England Area Health Service \\ ${ }^{\mathrm{B}} \mathrm{NSW}$ Department of Premier and Cabinet \\ ${ }^{\mathrm{C}}$ Corresponding author. Email: \\ Venessa.Wells@hnehealth.nsw.gov.au
}

\begin{abstract}
The Lower Hunter Regional Strategy prepared by the Hunter Department of Planning identifies how development in the region will be managed on a sustainable basis over the next 25 years. In order to inform decision-makers about the potential social and health impacts arising from the proposed population increase, the Hunter Regional Coordination Management Group, in collaboration with the NSW Premier's Department and Hunter New England Health, completed an equity-focussed social impact assessment of the strategy. The assessment illustrates how equity can be systematically addressed within an impact assessment process and provides insight into the mechanisms which led to equity considerations influencing the policy and planning agenda.
\end{abstract}

Population growth and its distribution, along with the availability of social and other services, have the potential to significantly affect the health and wellbeing of communities, both existing and new. ${ }^{1,2} \mathrm{~A}$ holistic approach to planning for population growth is required that incorporates an assessment of impacts on health and wellbeing, as well as on the environment and economy. ${ }^{3}$ One process that investigates these impacts is social impact assessment.

The Lower Hunter Regional Strategy, prepared by the Hunter Department of Planning, identifies how development in the region will be managed on a sustainable basis over the next 25 years in 35 sites that were configured by geographic location. The Department released a draft strategy in November 2005 and invited agencies and community members to comment by January 2006 . The strategy, which projects a population increase of 125000 people, has the potential to influence the health and social wellbeing of the community and the equitable access to and distribution of services across the region. The Hunter Regional Coordination Management Group, in collaboration with the NSW Premier's Department and Hunter New England Health, identified the need for a whole of government or multi-agency response to the draft strategy and consequently formed the social impact assessment Working Group to coordinate this response.

A social impact assessment provides the framework within which predictions can be made regarding the potential positive and negative impacts of a proposal while it is at the planning stage, to both maximise desired outcomes and minimise the costs or losses to communities. ${ }^{4}$ The Working Group agreed that it was important to consider the social and health impacts of the strategy by conducting a social impact assessment.

Currently, within the Hunter region people experience varying levels of vulnerability. ${ }^{5}$ The Working Group defined a vulnerable population as a subgroup of the overall population that is at higher risk of problem(s) that could be defined by age, gender, ethnicity or health status. To ensure that further vulnerabilities were not created by the strategy, and given that vulnerability is distributed inequitably across the Hunter region, the Working Group agreed that the assessment would have an equity focus. The aims of the social impact assessment were to: (1) assess levels of existing social vulnerability and access to services within the geographical sites identified by the strategy and (2) make recommendations based on the assessment of the appropriateness of proposed growth areas.

Equity was systematically addressed within the social impact assessment process by the use of an 'equity lens' ${ }^{6}$ This enabled the Working Group to assess whether the impact of increasing population in the proposed development areas would have a positive, negative or neutral impact on the wellbeing of the proposed communities, and if there would be a beneficial impact on wellbeing from the proposed population growth. In order to apply the 'equity lens' when deciding if the impact of implementing the strategy, whether negative or positive, was fair and just, the Working Group established a set of criteria which asked:

- Are we creating vulnerable communities?

- Are we increasing vulnerability?

- Are we re-allocating vulnerabilities? 
For ease of analysis and to ensure that the recommendations were practical, the 35 sites were clustered to 17 sites. A social vulnerability profile was created for each site to identify the impacts of the proposed population growth. This profile was based on a set of indicators that reflected the social determinants of health and well being (Table 1). These indicators were supplied by each agency participating in the Working Group and were based on their established links to social wellbeing and whether they were measurable at a collector district level. For each indicator a literature review established the evidence providing the link between the indicator and the effect on social wellbeing (see Table 1). These indicators were plotted for each of the 17 aggregate geographical sites to create a vulnerability profile. A consensus process was used by the Working Group to categorise the social vulnerability of the sites.

In addition to the social vulnerability profile, each agency represented within the Working Group was then asked to individually review the identified impacts for the 17 sites and comment on the findings according to each site's: (a) current level of social vulnerability, (b) current service capacity and (c) potential service capacity in the context of the proposed population growth.

The assessments of service capacity and the outcomes of the vulnerability assessment formed the basis of recommendations to the Hunter Department of Planning. The recommendations were framed to answer the question: 'What would need to occur for the area to accommodate the proposed population growth?' The results of the social impact assessment were submitted to the Hunter Department of Planning on behalf of the Hunter Regional Coordination Management Group, as a submission during the phase inviting public comment.

The recommendations were:

- strategic directions to be used to underpin regional planning in the Lower Hunter

Table 1. Indicators used to determine the level of social vulnerability at $\mathbf{1 7}$ geographical sites covered by the Lower Hunter Regional Strategy

- Percentage of new dwellings within walkable distance of public transport (over five kilometres) ${ }^{7}$

- Individual and household weekly income

- Employment and unemployment rates

- Smoking rates among pregnant mothers ${ }^{7-9}$

- Socio-economic indexes for areas - socio-economic disadvantage $\mathrm{e}^{7,10}$

- Socio-economic indexes for areas - index of economic resources

- Educational attainment score ${ }^{10-13}$

- Percentage of home ownership ${ }^{14}$

- Volunteer rates ${ }^{15,16}$

- Average distances nearest public transport
- changes to infrastructure within vulnerable sites for the area to accommodate the proposed population growth

- ongoing monitoring of social vulnerability levels.

Feedback from the Hunter Department of Planning indicated that these recommendations were considered in the development of the final strategy.

The social impact assessment was a valuable tool to facilitate a whole of government approach to population and infrastructure planning and provide support to decisionmakers in considering the potential consequences of their decisions. This social impact assessment also illustrates how equity can be systematically addressed within the process of impact assessment and provides practitioners with a practical example of how equity considerations can influence decision-makers.

\section{Acknowledgements}

The social impact assessment of the Lower Hunter Regional Strategy was undertaken in collaboration with representatives of the Hunter Regional Coordination Management Group and managed by NSW Premier's Department, Hunter Branch and Hunter New England Population Health, with funding provided by NSW Health. We would like to acknowledge the significant contribution of work by the members of the Hunter Regional Coordination Management Group. We would also like to thank the Centre for Health Equity Training, Research and Evaluation (CHETRE) for their support throughout the project.

\section{References}

1. McMicheal AJ, Powles JW. Human numbers, environment, sustainability and health. BMJ 1999; 319: 977-80.

2. House of Representatives, Standing Committee on Environment and Heritage. Sustainable cities. Canberra: The Parliament of the Commonwealth of Australia, 2005. Available from http://www.aph.gov.au/house/committee/environ/cities/ report/fullreport.pdf

3. Srinivasan S, O'Fallon LR, Dearry A. Creating healthy communities, healthy homes, healthy people: Initiating a research agenda on the built environment and public health. Am J Public Health 2003; 93(9): 1446-50.

4. Signal L. Tackling health inequalities through health promotion action. Health Promotion Forum of New Zealand Newsletter 2002; 56: 10.

5. The Regional Coordination Management Group Social Impact Assessment Working Group. Lower Hunter Regional Strategy: social impact statement. Unpublished report.

6. Cox G, Miers S. Social impact assessment for local governments. a handbook for councillors, town planners and social planners. Sydney: Local Government and Shires Association, 1995.

7. World Health Organization Regional Office for Europe. Social determinants of health: the solid facts. Copenhagen: World Health Organization Regional Office for Europe, 1998.

8. Walsh RA, Lowe JB, Hopkins PJ. Quitting smoking in pregnancy. Med J Aust 2001; 175: 320-3. 
9. Vinson T. Unequal in life: the distribution of social disadvantage in Victoria and New South Wales. Richmond, Vic.: The Ignatius Centre for Social Policy and Research and Jesuit Social Services, 1999.

10. Population Health Division. The health of the people of New South Wales: report of the Chief Health officer, 2004. Sydney: NSW Department of Health, 2004.

11. Commonwealth of Australia. Chapter 7: Education and training. In: A hand up not a hand out: renewing the fight against poverty. Report on poverty and financial hardship. Canberra : Australian Government, 2005.

12. Zappalà G, Considine G. Educational performance among school students from financially disadvantaged backgrounds. Working Paper No. 4. Sydney: The Smith Family, 2001.
13. King A. The cost to Australia of early school leaving. Report commissioned by the Dusseldorp Skills Forum. Canberra: National Centre for Social and Economic Modelling, University of Canberra, 1999.

14. Bradbury B, Chalmers J. Housing, location and employment. Australian Housing and Urban Research Institute, University of NSW and University of Western Sydney Research Centre, 2003.

15. Public Health Agency of Canada. Volunteer participation as a contributor to healthy communities. Ottawa: Public Health Agency of Canada, 2002.

16. Hyyppa MT, Maki J. Social participation and health in a community rich in stock of social capital. Health Educ Res 2003; 18(6): 770-9. doi:10.1093/her/cyf044

\section{NSW Public Health Bulletin Subscription Form and Electronic Early Alert Service}

To subscribe to the hard copy of the NSW Public Health Bulletin or to change your subscription details please complete this form and return it by email (phbulletin@doh.health.nsw.gov.au) or fax (61 29391 9232).

The Bulletin can be accessed electronically from www.publish.csiro.au/journals/phb. Subscribe to the Early Alert service to be notified as soon as it appears online (http://publish.csiro.au/nid/226.htm?nid=25\&aid=685).

\section{Subscription information}

$\square$ I wish to receive the NSW Public Health Bulletin:

My details are as follows

Name:

Organisation:

Mailing Address:

State: Postcode: Country:

Telephone: Facsimile:

Email:

\section{Change of Address}

I wish to change my mailing details, as follows:

Name:

From: [Insert old address]

To: [Insert new address] 